\title{
3 Research Square

\section{Prognostic Value of High-sensitivity Cardiac Troponin in Non-cardiac Surgical Patients in Intensive Care Units}

Jitain Sivarajah

Frankston Hospital

Michael Toolis

Dandenong Hospital

Samantha Seminoff

Frankston Hospital

Jesse Smith

Frankston Hospital

Vikram Bhalla

Frankston Hospital

Eldho Paul

Frankston Hospital

Ravindranath Tiruvoipati ( $\boldsymbol{\nabla}$ travindranath@hotmail.com )

Frankston Hospital https://orcid.org/0000-0003-3800-902X

Research

Keywords: Myocardial infarction, Cardiac troponin, Mortality, Surgery, Intensive care

Posted Date: August 3rd, 2021

DOI: https://doi.org/10.21203/rs.3.rs-754326/v1

License: (c) (i) This work is licensed under a Creative Commons Attribution 4.0 International License. Read Full License 


\section{Abstract}

Background: Type II myocardial injury following surgical procedures is associated with adverse outcomes. The prognostic value of prognostic value of high-sensitivity cardiac troponin (hs-cTn) due to type II myocardial injury in surgical patients admitted to intensive care unit (ICU) remains unclear.

The aim of this study was to assess prognostic value of hs-cTn in type II acute myocardial injury in noncardiac surgical patients requiring post-operative ICU admission.

Methods: Retrospective analysis of patients admitted to two level III ICUs following surgery and had hscTn measured on the day of ICU admission. Patients who had type I acute myocardial infarction (AMI) during their admission were excluded from the study. The primary outcome was hospital mortality. Secondary outcomes included ICU mortality, ICU length of stay (LOS) and hospital LOS.

Results: A total of 420 patients were included. On univariable analysis, higher hs-cTn was associated with increased hospital mortality (14.6\% vs $6.3 \%, p=0.008)$, ICU LOS $(41.1$, vs 25 hours, $p=0.004)$ and hospital LOS (253 hours vs 193 hours, $p=0.02$ ). On multivariable analysis, hs-cTn was not independently associated with increased risk of hospital mortality. However, in patients who had elective surgery, hs-cTn was associated with increased risk (OR 1.048; $95 \% \mathrm{Cl} 1.004-1.094 ; \mathrm{p}=0.031)$ of hospital morality with area under the receiver operating characteristic curves of 0.753 (95\% $\mathrm{Cl} 0.598-0.908)$.

Conclusions: In elective surgical patients, hs-cTn was associated with increased risk of mortality. Larger multicentre studies are required to confirm this association that may assist in risk stratification of elective surgical patients requiring ICU admission.

\section{Introduction}

Many patients are admitted post-operatively to intensive care units (ICU) after undergoing both elective and emergency surgery ${ }^{1}$. The goal of such post-operative admissions to ICU as opposed to regular hospital ward locations is to provide an environment which optimises patient outcomes by allowing clinicians to closely monitor, rapidly identify and act upon evidence of patient deterioration 2,3 .

Mortality related to myocardial injury is one of the leading causes of postoperative death within 30 days of non-cardiac surgery 4,5 . The mortality is mostly due to perioperative acute myocardial infarction (AMI) due to myocardial injury caused by coronary artery diseases including plaque rupture or thrombosis (type I AMI) or due to supply - demand mismatch (type II AMI) due to several post-operative conditions including hypotension, tachycardia, hypoxemia and sepsis ${ }^{6}$. Blood measurements of high sensitive cardiac troponin (hs-cTn) are a well-known predictor of mortality and other adverse patient outcomes in multiple settings ${ }^{7-10}$. The predictive value of cardiac troponin in the post-operative phase has been studied in multiple subsets of post-operative surgical patients ${ }^{11-13}$. These studies including patients with type I and type II AMI reported that cardiac troponin or hs-cTn had independent association of increased risk of mortality. High sensitive cardiac troponin assays detect lower levels of troponins as 
compared to the more traditional troponin assay. While this increased sensitivity plays an important role in patients with type I AMI, it is uncertain at this stage as to how hs-cTn are to be interpreted in the setting of type II AMI during perioperative period.

While the treatment options of type I AMI are well established targeting revascularisation, the management of type II AMI in perioperative setting is evolving. The management is largely supportive care aimed to correct the imbalance between oxygen supply - demand mismatch ${ }^{14}$. It is unknown if hscTn predicts short term mortality in type II AMI post-operative patients as none of the earlier studies specifically investigated this group of patients. Furthermore earlier studies included patients managed in surgical wards where vital signs are evaluated only every 4-8 hours contrasting to continuous monitoring of patients intraoperatively or in intensive care units post operatively $5,11,15$.

To the best of our knowledge, the role of hs-cTn in type II myocardial injury and in patients admitted specifically to ICU (where patients are monitored continuously) following elective and emergency surgery has not yet been studied.

Our study aimed to investigate the association of hs-cTn due to type II myocardial injury with hospital mortality in non-cardiac surgical patients admitted to ICU following both elective and non-elective surgery.

\section{Methods}

\section{Ethical considerations}

Ethics approval was obtained from the Human Research and Ethics Committee of Peninsula Health (Reference number QA/69001/PH-2020-234264) and Monash Health (Reference number QA/71890/MonH-2020-241855). Informed consent was waived by ethics committees as data was already collected as part of routine quality assurance processes.

Postoperative patients admitted to ICU over a four year period from April 2016 to May 2020 which corresponded to the introduction of hs-cTn measurements at our study sites were screened. Patients were included in the study if they were admitted to ICU following elective or emergency surgery and had a hscTn assay on the day of admission to ICU. Patients were excluded if they had been diagnosed with an acute myocardial infarction perioperatively or during their current hospital admission. Patients included were stratified into two groups based on their serum hs-cTn: a low troponin group $(<16 \mathrm{ng} / \mathrm{L}$ in females and $<34 \mathrm{ng} / \mathrm{L}$ in males) and a high troponin group ( $>15 \mathrm{ng} / \mathrm{L}$ in females and $>33 \mathrm{ng} / \mathrm{L}$ in males). These values were based on the normal reference range in our laboratories. Data was collected from our ICU databases, hospital pathology databases and individual patient case records.

Data on physiological, laboratory variables and scores derived from scoring systems (American Society of Anaesthesiologists physical status classification system [ASA] and acute physiology age and chronic health evaluation III score [APACHE III]) during the first 24 hours were collected, and the most abnormal values during the first 24 hours were analysed. The biochemical variables analysed included high- 
sensitivity troponins, lactate, sodium, potassium, blood glucose, haemoglobin, white cell count, platelet count, bilirubin, albumin, creatinine and urea. Physiological variables included age, sex, heart rate, blood pressure (systolic, diastolic and mean), respiratory rate, temperature, Glascow Coma Scale, FiO2 requirements, $\mathrm{PaO}_{2}, \mathrm{PaCO}_{2}, \mathrm{pH}_{1} \mathrm{HCO}_{3}{ }^{-}$, whether or not invasive or non-invasive ventilation was used and whether or not inotropes or vasopressors were used during the first 24 hours of ICU admission.

Patient management in ICU. All patients admitted to ICU had fixed patient to nurse ratio depending on the monitoring and treatments required. Patients were nursed 1:1 if the patients required mechanical ventilation or had haemodynamic instability that required vasoactive medications and 1:2 otherwise. All patients had continues monitoring of ECG, oxygen saturation, blood pressure and respiratory rate during their ICU stay. All patients had ECG on admission to ICU and at least once daily while in ICU. Over $90 \%$ of the patients had invasive haemodynamic monitoring using intra-arterial catheters.

The primary outcome was in-hospital mortality. The secondary outcomes included ICU mortality, ICU and hospital length of stay, development of acute renal failure and in patient cardiac arrest. ARF was defined as a 24 hour urine output $<410 \mathrm{ml}$ and serum creatinine $\geq 133 \mu \mathrm{mol} / \mathrm{L}$ and no chronic dialysis.

\section{Statistical analysis}

All analyses were performed with SAS software version 9.4 (SAS Institute, Cary, NC, USA). Baseline and outcome variables were compared between groups (high vs low troponin) using chi-square tests or Fisher's exact tests, as appropriate, for categorical variables; Student's t tests for normally distributed continuous variables; and Wilcoxon rank sum tests otherwise, with results presented as frequency (proportion), mean (SD), and median (interquartile range [IQR]), respectively. Univariable and multivariable analyses for hospital mortality were performed using logistic regression modelling with results presented as odds ratios (OR) and $95 \%$ confidence intervals $(95 \% \mathrm{Cl})$. Variables with a $p<0.05$ on univariable analysis or those deemed to be clinically relevant were considered for inclusion in the multivariable regression model. The interaction between troponin and type of surgery (elective vs emergency) was assessed by fitting main effects for troponin, type of surgery and their two-way interactions. The prognostic value of troponin in predicting hospital mortality was assessed by calculating area under the receiver operating characteristic curves (AUROC). All calculated $p$ values were two-tailed and $p<0.05$ indicated statistical significance.

\section{Results}

During the study period, a total of 2270 patients were admitted to ICUs post-operatively following either emergency or elective surgical procedures. Of these patients, $420(18.5 \%)$ were included in the analysis. 1850 patients were excluded due to a diagnoses of acute myocardial infarction during their admission (n $=50$ ) and troponins were not measured within the first 24 hours of ICU admission in 1800 patients. Inclusion and exclusion of patients in the study are presented in Fig. 1. 
$24 \%(103 / 420)$ of patients showed an elevation in hs-cTn during the first 24 hours of their ICU admission. Table 1 presents a comparison of demographics, physiological and biochemical characteristics of patients with elevated and normal hs-cTn. Patients with elevated hs-cTn had a median of $53 \mathrm{ng} / \mathrm{L}$ [36$146]$ as compared to normal $6 \mathrm{ng} / \mathrm{L}[3.2-12](p<0.001)$. 
Table 1

Comparison of demographical, physiological and biochemical characteristics at time of admission of patients to Intensive Care.

\begin{tabular}{|c|c|c|c|}
\hline Variable & $\begin{array}{l}\text { Normal-Troponin } \\
\text { group }(n=317)\end{array}$ & $\begin{array}{l}\text { Elevated-Troponin } \\
\text { group }(n=103)\end{array}$ & P-Value \\
\hline Age $(n=420)$ & $71.2[60.5-79.1]$ & $76.5[65.3-83.7]$ & 0.004 \\
\hline Sex, $M(n=420)$ & $68.8 \%(218)$ & $46.6 \%(48)$ & $<0.0001$ \\
\hline Comorbidities & $2.2 \%(7)$ & $0.971 \%(1)$ & 0.43 \\
\hline Cardiovascular disease $(n=420)$ & $1.6 \%(5)$ & $3.9 \%(4)$ & 0.16 \\
\hline Respiratory disease $(n=420)$ & $2.2 \%(7)$ & $4.9 \%(5)$ & 0.16 \\
\hline Liver disease $(n=420)$ & $1.3 \%(4)$ & $2.9 \%(3)$ & 0.37 \\
\hline Renal disease $(n=420)$ & $2.2 \%(7)$ & $5.8 \%(6)$ & 0.07 \\
\hline Immunosuppressed $(n=420)$ & $2.5 \%(8)$ & $2.9 \%(3)$ & 0.83 \\
\hline \multicolumn{4}{|l|}{ Metastatic malignancy $(n=420)$} \\
\hline Elective Surgery $(n=419)$ & $61.1 \%(193)$ & $34 \%(35)$ & $<0.0001$ \\
\hline Vital signs & $93.5(19.2)$ & $98.4(22.4)$ & 0.028 \\
\hline Heart rate $(/ \min )(n=420)$ & $150(20)$ & $148(24.6)$ & 0.45 \\
\hline Systolic Blood Pressure $(\mathrm{mmHg})(n=420)$ & 70 [63-82] & $68[60-80]$ & 0.038 \\
\hline Diastolic Blood Pressure $(\mathrm{mmHg})(n=420)$ & $97[88-106]$ & $93[85-104]$ & 0.045 \\
\hline Mean Blood Pressure $(\mathrm{mmHg})(\mathrm{n}=420)$ & $22.4(4.29)$ & $23.4(5.61)$ & 0.07 \\
\hline Respiratory Rate $(/ \min )(n=415)$ & $36.6(0.697)$ & $36.8(0.785)$ & 0.042 \\
\hline Temperature $\left({ }^{\circ} \mathrm{C}\right)(\mathrm{n}=420)$ & $14.6(0.969)$ & $14.5(1.12)$ & 0.5 \\
\hline Glascow Coma Scale $(n=414)$ & $0.28[0.21-0.3]$ & $0.3[0.25-0.45]$ & $<0.0001$ \\
\hline \multicolumn{4}{|l|}{$\mathrm{FiO}_{2}$ Requirements $(\mathrm{n}=389)$} \\
\hline Severity of illness & $3[3-3]$ & $3[3-4]$ & $<0.0001$ \\
\hline ASA $(n=391)$ & $50.2(16.3)$ & $65(21.4)$ & $<0.0001$ \\
\hline APACHE III $(n=418)$ & $22.7 \%(70)$ & $39.8 \%(39)$ & 0.001 \\
\hline Inotropes used $\left(D_{0}\right)(n=406)$ & $24.7 \%(53)$ & $45.9 \%(34)$ & 0.001 \\
\hline Invasive ventilation $\left(D_{0}\right)(n=289)$ & $5.7 \%(12)$ & $5.6 \%(4)$ & 0.97 \\
\hline Non-invasive ventilation $(n=284)$ & & & \\
\hline
\end{tabular}




\begin{tabular}{|c|c|c|c|}
\hline Variable & $\begin{array}{l}\text { Normal-Troponin } \\
\text { group }(n=317)\end{array}$ & $\begin{array}{l}\text { Elevated-Troponin } \\
\text { group }(n=103)\end{array}$ & P-Value \\
\hline Investigations & $1.4[1-2.5]$ & $2[1.3-3.5]$ & $<0.0001$ \\
\hline Lactate $(n=397)$ & $7.37(0.067)$ & $7.34(0.09)$ & $<0.0001$ \\
\hline $\mathrm{pH}(\mathrm{n}=389)$ & 77 [69-100] & $78[69-120]$ & 0.37 \\
\hline $\mathrm{paO}_{2}(\mathrm{mmHg})(\mathrm{n}=389)$ & $40.2(6.51)$ & $39.9(8.77)$ & 0.77 \\
\hline $\mathrm{paCO}_{2}(\mathrm{mmHg})(\mathrm{n}=389)$ & $23.3(3.36)$ & $22(4.29)$ & 0.001 \\
\hline $\mathrm{HCO}{ }^{-}(\mathrm{mmol} / \mathrm{l})(\mathrm{n}=415)$ & $137(3)$ & $137(3.99)$ & 0.14 \\
\hline 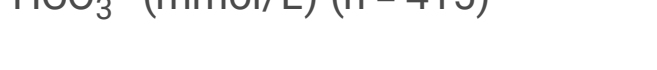 & $4.26(0.465)$ & $4.19(0.639)$ & 0.22 \\
\hline Sodium $(\mathrm{mmol} / \mathrm{L})(\mathrm{n}=418)$ & $9.79(3.24)$ & $10.3(4.55)$ & 0.18 \\
\hline Potassium $(\mathrm{mmol} / \mathrm{L})(\mathrm{n}=415)$ & $10.6(2.08)$ & $9.69(1.86)$ & $<0.0001$ \\
\hline Blood Glucose $(\mathrm{mmol} / \mathrm{L})(\mathrm{n}=411)$ & $13.9(6.5)$ & $15.8(9.46)$ & 0.031 \\
\hline Haemoglobin $(\mathrm{g} / \mathrm{dL})(\mathrm{n}=418)$ & 224 (109) & $207(90)$ & 0.17 \\
\hline White Cells $\left(x 10^{9} / L\right)(n=417)$ & $12[9-17]$ & $13[9-21]$ & 0.23 \\
\hline Platelets $\left(x 10^{9} / L\right)(n=417)$ & $28.6(5.58)$ & $25.4(5.56)$ & $<0.0001$ \\
\hline Serum Bilirubin $(\mu \mathrm{mol} / \mathrm{L})(n=415)$ & $82[66-106]$ & $112[74-204]$ & $<0.0001$ \\
\hline Serum Albumin $(g / L)(n=417)$ & $7[5.3-9.5]$ & $10.4[6.9-17.5]$ & $<0.0001$ \\
\hline \multicolumn{4}{|l|}{ Creatinine $(\mu \mathrm{mol} / \mathrm{L})(\mathrm{n}=418)$} \\
\hline \multicolumn{4}{|l|}{ Urea $(\mathrm{mmol} / \mathrm{L})(\mathrm{n}=418)$} \\
\hline \multicolumn{4}{|c|}{$\begin{array}{l}\text { Data presented with mean and standard deviation for Heart Rate, Respiratory Rate, Temperature, } \\
\text { Systolic BP, GCS, APACHE III, } \mathrm{pH}, \mathrm{PaCO}_{2}, \mathrm{HCO}_{3}{ }^{-} \text {, Sodium, Potassium, Blood Glucose, Haemoglobin, } \\
\text { White Cells, Platelets and Albumin and with median and interquartile ranges unless previous } \\
\text { specified. Vital signs presented as mean or median of highest recorded; } n=\text { number of patients where } \\
\text { data were available for analysis, } D_{0}-\text { Day of admission, ARF - Acute Renal Failure, LOS - Length of } \\
\text { Stay }\end{array}$} \\
\hline
\end{tabular}

Patients who had emergency surgery had a higher elevation of hs-cTn (13 ng/L [6-39] vs 7 [3.1-16.5]; $p$ $<0.001$ ) as comparted to elective surgical patients and had a higher ASA score (3[3-4] vs 3 [3-3]; $p<$ 0.01) and APACHE III scores (Mean 59.4 (SD 20.5) Vs 49.1 (15.9); $p<0.001$ ).

Table 2 presents the characteristics of patients who survived to hospital discharge versus those who died during their admission. Patients who died in hospital were older, had higher proportion of emergency surgery, higher ASA and APACHE III score and the need for inotropes and invasive mechanical ventilation. 
Table 2

Characteristics of patients who died in hospital and survived to hospital discharge.

\begin{tabular}{|c|c|c|c|}
\hline Variable & $\begin{array}{l}\text { Survived to Hospital Discharge (n } \\
=385 \text { ) }\end{array}$ & $\begin{array}{l}\text { Died in } \\
\text { Hospital } \\
(n=35)\end{array}$ & $\begin{array}{l}P \text { - } \\
\text { Value }\end{array}$ \\
\hline Age $(n=420)$ & $71.3[60.5-79.4]$ & $\begin{array}{l}79.2[72.3- \\
83.7]\end{array}$ & $<.0001$ \\
\hline Sex, $M(n=420)$ & $63.2 \%(244)$ & $62.9 \%(22)$ & 0.97 \\
\hline Comorbidities & $1.6 \%(6)$ & $5.7 \%(2)$ & 0.08 \\
\hline Cardiovascular disease $(n=420)$ & $2.3 \%(9)$ & $0 \%(0)$ & 1.00 \\
\hline Respiratory disease $(n=420)$ & $2.6 \%(10)$ & $5.7 \%(2)$ & 0.29 \\
\hline Liver disease $(n=420)$ & $1.3 \%(5)$ & $5.7 \%(2)$ & 0.05 \\
\hline Renal disease $(n=420)$ & $3.1 \%(12)$ & $2.9 \%(1)$ & 0.93 \\
\hline Immunosuppressed $(n=420)$ & $2.3 \%(9)$ & $5.7 \%(2)$ & 0.23 \\
\hline \multicolumn{4}{|l|}{ Metastatic malignancy $(n=420)$} \\
\hline Elective Surgery $(n=420)$ & $56.6 \%(218)$ & $28.6 \%(10)$ & 0.001 \\
\hline Vital signs & $93.1(19.3)$ & $111(21.7)$ & \multirow{2}{*}{$<0.0001$} \\
\hline Heart rate $(/ \min )(n=420)$ & $150(20.6)$ & $145(26.8)$ & \\
\hline Systolic Blood Pressure $(\mathrm{mmHg})(\mathrm{n}$ & $70[63-82]$ & $66[60-75]$ & \multirow{2}{*}{$\begin{array}{l}0.19 \\
0.09 \\
0.1\end{array}$} \\
\hline $\begin{array}{l}\text { Diastolic Blood Pressure }(\mathrm{mmHg})(\mathrm{n} \\
=420)\end{array}$ & $\begin{array}{l}96[87-106] \\
22.5(4.41)\end{array}$ & $\begin{array}{l}92[82-103] \\
24.2(6.64)\end{array}$ & \\
\hline $\begin{array}{l}\text { Mean Blood Pressure }(\mathrm{mmHg})(\mathrm{n}= \\
420)\end{array}$ & $36.6(0.684)$ & $36.8(1.05)$ & $\begin{array}{l}0.037 \\
0.18\end{array}$ \\
\hline Respiratory Rate $(/ \min )(n=416)$ & \multirow{2}{*}{$0.28[0.21-0.39]$} & \multirow{2}{*}{$\begin{array}{l}0.3[0.21- \\
0.7]\end{array}$} & 0.79 \\
\hline Temperature $\left({ }^{\circ} \mathrm{C}\right)(\mathrm{n}=420)$ & & & 0.07 \\
\hline Glascow Coma Scale $(n=415)$ & & & \\
\hline $\mathrm{FiO}_{2}$ Requirements $(\mathrm{n}=389)$ & & & \\
\hline
\end{tabular}




\begin{tabular}{|c|c|c|c|}
\hline Variable & $\begin{array}{l}\text { Survived to Hospital Discharge (n } \\
=385 \text { ) }\end{array}$ & $\begin{array}{l}\text { Died in } \\
\text { Hospital } \\
(n=35)\end{array}$ & $\begin{array}{l}P \text { - } \\
\text { Value }\end{array}$ \\
\hline Severity of illness & $3[3-4]$ & $4[3-4]$ & \multirow{2}{*}{$\begin{array}{l}< \\
0.0001\end{array}$} \\
\hline ASA $(n=392)$ & $51.7(17.1)$ & $77(20.6)$ & \\
\hline APACHE III $(n=419)$ & $24.9 \%(93)$ & $47.1 \%(16)$ & $<.0001$ \\
\hline Inotropes used $\left(D_{0}\right)(n=407)$ & $23.8 \%(92)$ & $47.1 \%(16)$ & 0.005 \\
\hline Invasive ventilation $\left(D_{0}\right)(n=420)$ & $5.7 \%(15)$ & $4.3 \%(1)$ & 0.003 \\
\hline \multicolumn{3}{|l|}{ Non-invasive ventilation $(n=285)$} & 0.78 \\
\hline Investigations & $1.5[1-2.6]$ & $2.1[1.2-3.1]$ & 0.05 \\
\hline Lactate $(n=397)$ & $7.36(0.07)$ & $7.33(0.107)$ & 0.008 \\
\hline $\mathrm{pH}(\mathrm{n}=389)$ & 78 [69-103] & $78[68-141]$ & 0.85 \\
\hline $\mathrm{paO}_{2}(\mathrm{mmHg})(\mathrm{n}=389)$ & $40.2(6.73)$ & $38.6(10.3)$ & 0.2 \\
\hline $\mathrm{paCO}_{2}(\mathrm{mmHg})(\mathrm{n}=389)$ & $23.3(3.41)$ & $20.1(4.89)$ & $<0.0001$ \\
\hline $\mathrm{HCO}_{3}^{-}(\mathrm{mmol} / \mathrm{L})(\mathrm{n}=416)$ & $\begin{array}{l}137(3.27) \\
4.55(0.521)\end{array}$ & $\begin{array}{l}138(3.14) \\
4.63(0.767)\end{array}$ & 0.049 \\
\hline Sodium $(\mathrm{mmol} / \mathrm{L})(\mathrm{n}=419)$ & $6.94(2.4)$ & $6.16(1.57)$ & \multirow{2}{*}{0.06} \\
\hline Potassium $(\mathrm{mmol} / \mathrm{L})(\mathrm{n}=416)$ & $10.4(2.03)$ & $9.66(2.21)$ & \\
\hline Blood Glucose $(\mathrm{mmol} / \mathrm{L})(\mathrm{n}=411)$ & $14.4(7.43)$ & $14.1(6.79)$ & 0.043 \\
\hline Haemoglobin $(\mathrm{g} / \mathrm{dL})(\mathrm{n}=419)$ & $240(115)$ & 248 (119) & 0.82 \\
\hline White Cells $\left(x 10^{9} / L\right)(n=418)$ & 12 [9-18] & 17.5 [11-25] & \multirow{2}{*}{0.003} \\
\hline Platelets $\left(x 10^{9} / L\right)(n=418)$ & $28.3(5.47)$ & $22.6(6.1)$ & \\
\hline Serum Bilirubin $(\mu \mathrm{mol} / \mathrm{L})(\mathrm{n}=416)$ & $84[66-115]$ & $131[78-251]$ & 0.0001 \\
\hline Serum Albumin $(\mathrm{g} / \mathrm{L})(\mathrm{n}=418)$ & $7.4[5.7-10.2]$ & $10.4[8-21.3]$ & 0.002 \\
\hline \multicolumn{3}{|l|}{ Creatinine $(\mu \mathrm{mol} / \mathrm{L})(\mathrm{n}=419)$} & $\begin{array}{l}< \\
0.0001\end{array}$ \\
\hline \multicolumn{4}{|c|}{$\begin{array}{l}\text { Data presented with mean and standard deviation for Heart Rate, Systolic BP, Respiratory Rate, GCS, } \\
\text { APACHE III, PaCO2 }{ }_{2}, \mathrm{HCO}_{3}{ }^{-} \text {, Sodium, Potassium, Blood Glucose, Haemoglobin, White Cells, Platelets } \\
\text { and Albumin, and with median and interquartile ranges unless previous specified. Vital signs } \\
\text { presented as mean or median of highest recorded; } n=\text { number of patients where data were available } \\
\text { for analysis, } D_{0}-\text { Day of admission, ARF - Acute Renal Failure, LOS - Length of Stay }\end{array}$} \\
\hline
\end{tabular}




\section{Table 3. Comparisons of outcomes}

\begin{tabular}{llll} 
Variable & $\begin{array}{l}\text { Normal-Troponin } \\
\text { group }(\mathrm{n}=317)\end{array}$ & $\begin{array}{l}\text { Elevated-Troponin } \\
\text { group }(\mathrm{n}=103)\end{array}$ & P-Value \\
Primary Outcome & $6.3 \%(20)$ & $14.6 \%(15)$ & 0.008 \\
In-hospital mortality $(\mathrm{n}=420)$ & $2.2 \%(7)$ & $5.8 \%(6)$ & 0.07 \\
Secondary Outcomes & $25[19.8-45]$ & $41.1[21-71.3]$ & 0.004 \\
ICU mortality $(\mathrm{n}=420)$ & $193[122-358]$ & $253[137-460]$ & 0.02 \\
ICU LOS (hours) $(\mathrm{n}=420)$ & $1 \%(3)$ & $7.2 \%(7)$ & 0.001 \\
Hospital LOS (hours) $(\mathrm{n}=420)$ & $0.316 \%(1)$ & $2.9 \%(3)$ & 0.048 \\
$\begin{array}{l}\text { Development of ARF }(\mathrm{n}=398) \\
\text { Inpatient Cardiac Arrest }(\mathrm{n}=419)\end{array}$ & & & \\
$\begin{array}{l}\text { Data presented as percentage values and actual values respectively, with media and interquartile } \\
\text { range for ICU LOS and Hospital LOS, ICU - Intensive Care Unit, LOS - Length of stay, ARF - Acute } \\
\text { Renal Failure }\end{array}$ & \\
\hline
\end{tabular}

On univariate analysis, the primary outcome of in-hospital mortality was higher in elevated hs-cTn group $(14.6 \%$ Vs $6.3 \% ; p=0.008)$ (Table 3). Patients in elevated hs-cTn group also had a higher incidence of ARF, inpatient cardiac arrest, longer ICU and hospital LOS. There was a strong trend towards increased ICU mortality in the elevated hs-cTn group, but this did not reach statistical significance $(5.8 \%$ Vs $2.2 \%$; $p$ $=0.07)$ (Table 3$)$.

Multivariate logistic regression analysis including all postoperative patients revealed highest heart-rate (OR 1.02; 95\% Cl 1.001-1.04; $p=0.036$ ) and APACHE-III score (OR 1.06; 95\% $\mathrm{Cl} 1.04-1.08 ; \mathrm{p}<0.0001$ ) were independently associated with hospital mortality. High sensitive cardiac troponin on day of admission to ICU was not found to be an independent predictor of in-hospital mortality (OR $0.998,95 \% \mathrm{Cl}$ $0.982-1.015 ; p=0.85$ ). The AUROC (Fig. 2) for this model was 0.689 ( $95 \% \mathrm{Cl}: 0.596$ to 0.782 ). As there was a significant interaction $(p=0.049)$ between hs-cTn and type of surgery (elective vs emergency), analysis was conducted separately for the subgroup of patients who had elective or emergency surgery. This showed that hs-cTn were associated with increased risk of hospital mortality (OR 1.048; $95 \% \mathrm{Cl}$ $1.004-1.094 ; p=0.031$ ) in elective surgical patients with AUROC of $0.753(95 \% \mathrm{Cl} 0.598-0.908)$, but not in emergency surgical patients (OR 1.003; $95 \% \mathrm{Cl} 0.995-1.012 ; \mathrm{p}=0.43$; AUROC $0.611,95 \% \mathrm{Cl} 0.485-$ 0.737).

\section{Discussion}


In this double-centre retrospective study which included over 400 postoperative patients requiring ICU admission at two ICUs after emergency and elective surgery, we aimed to investigate whether highsensitivity troponin was an independent predictor of in-hospital mortality. After adjusting for confounders with multivariable analysis, high-sensitivity troponin was not found to be independently associated with in-hospital mortality. In the subgroup of patients admitted to ICU after elective surgery, however, elevated high-sensitivity troponins did reveal an association with mortality.

Routine use of high-sensitivity troponins is becoming increasingly common, due to their improved detection of myocardial injury. With their benefit demonstrated in acute coronary syndromes ${ }^{16}$ and the role of the routine high sensitive cardiac troponin assay being established as a marker of critical illness in non-cardiac conditions ${ }^{7,13}$, including as an association with mortality, the role of the high-sensitivity troponins in risk stratification of patients undergoing surgery is evolving ${ }^{6}$. In patients after cardiac surgery, high sensitive cardiac troponin were independently associated with increased mortality ${ }^{17}$. Some studies including patients after non cardiac surgery showed an independent association of high sensitive troponin and increased mortality ${ }^{11}$. However in studies that specifically included high risk non-cardiac surgical patients, high sensitive troponins were not associated with increased risk of mortality ${ }^{18}$.

In our study overall high sensitive troponins were not independently associated with increased hospital mortality. These results are different to some of the other studies reporting on the association of hs-cTn on mortality in non-cardiac surgical patients ${ }^{11,19}$. The differences are likely due to the case mix of the patients included as well as the postoperative interventions. The majority of patients develop AMI within 48 hours after surgical procedures 4,14 . Our study included patients who were closely monitored and managed in intensive care units with median duration of ICU stay of about 26 hours. This monitoring and management will have prevented or have timely managed hypoxemia or hypotension. Such management is likely to improve outcomes in type II myocardial ischemia.

Nevertheless, our study showed that elevated hs-cTn was associated with mortality in patients undergoing elective surgery but not in patients following emergency surgery. While the cause for an increased risk of mortality in elective surgical patients is not clear from our study, but it highlights the need for closer monitoring of elective surgical patients with elevated hs-cTn. It appears that even smaller elevation of hs-cTn in elective surgical patients is associated with higher risk of hospital mortality.

Our study has multiple strengths worth highlighting. Firstly, ours is the first study to specifically evaluate the prognostic value of post-operative hs-cTn measurements in non-cardiac surgical patients admitted to the ICU postoperatively. Our study specifically investigated patients with type II AMI that is pathophysiologically different from other types of AMI caused by coronary artery disease. Furthermore, we had older patients (median age 72.2 year IQR 61.3-79.9 years) in our study as compared to other studies that had younger patients ${ }^{11}$. Older patients are likely to have more cardiac comorbidities are likely have to have higher risk of cardiac death post operatively. Prior studies have addressed post-operative patient populations admitted to either intensive-care or ward-based settings ${ }^{11}$ and anaesthetic recovery areas ${ }^{19}$ 
but not specifically to the ICU alone. Our databases allowed us to have clear and robust data collection, and the exclusion of any myocardial infarctions specifically investigates the role of hs-cTn in nonischaemic (type II) myocardial injury during the perioperative period. The stratification of hs-cTn levels based on the sex of patients provides a more reliable assessment of myocardial injury independent of the sex of the patients included. Another strength of our study is that it was conducted over two different hospitals which are both part of two independent health networks and have slightly different surgical case mixes. We expect this study will be generalisable to similar centres.

Our study also has weaknesses. Firstly, our study was retrospective by design. Our surgical case mix did also not include trauma patients, or patients undergoing cardiothoracic or neurosurgical procedures who potentially have higher illness severities. Moreover, despite a large number of patients screened, only a fraction of eligible patients actually had at least one high-sensitive troponin measured in the first 24 hours of their ICU admission (564 in total, including patients excluded as per methodology; $24.8 \%$ ).

Important future directions exist for our study. In particular, a larger multicentre prospective study looking at the prognostic value of post-operative hs-cTn in patients admitted to ICUs would yield more conclusive results esp on the role of hs-cTn in elective surgical patients.

\section{Conclusion}

Elevated hs-cTn levels are associated with increased in hospital mortality in patients admitted to ICU after elective surgery. Larger multicentre studies are required to confirm this association that may assist in risk stratification of elective surgical patients and to further evaluate hs-cTn role in emergency surgical patients requiring post-operative admission to ICU.

\section{Abbreviations}

AMI

Acute myocardial infarction

APACHE III

Acute Physiology And Chronic Health Evaluation III

ARF

Acute renal failure

ASA

American Society of Anaesthesiologists (Classification system)

$\mathrm{Cl}$

Confidence interval

ECG

Electrocardiogram

$\mathrm{FiO}_{2}$

Fraction of inspired oxygen 
hs-cTn

High-sensitivity cardiac troponin

ICU

Intensive care unit

IQR

Interquartile range

LOS

Length of stay

OR

Odds ratio

SAS

Statistical Analysis System

SD

Standard Deviation

\section{Declarations}

Ethics approval and consent to participate: Ethics approval was obtained from the Human Research and Ethics Committee of Peninsula Health (Reference number QA/69001/PH-2020-234264) and Monash Health (Reference number QA/71890/MonH-2020-241855). Informed consent was waived by ethics committees as data was already collected as part of routine quality assurance processes.

Consent for publication: Not applicable

Availability of data and material: All data generated or analysed during this study are included in this published article

Competing interests: The Authors declare that they have no competing interests

\section{Funding: Nil}

\section{Authors' contributions:}

Jitain Sivarajah: Data curation, methodology, original draft writing, review \& editing

Michael Toolis: Data curation; original draft writing, review \& editing.

Samantha Seminoff: Data curation; draft review and revision and editing.

Jesse Smith: Data curation; draft review and revision and editing.

Vikram Bhalla: Data curation; draft review and revision and editing

Eldho Paul: Formal analysis, draft review and revision and editing. 
Ravindranath Tiruvoipati: Conceptualization, methodology, Supervision, original draft writing, review \& editing.

Acknowledgements: Not applicable

\section{References}

1. Jerath A, Laupacis A, Austin PC, Wunsch H and Wijeysundera DN. Intensive care utilization following major noncardiac surgical procedures in Ontario, Canada: a population-based study. Intensive Care Med. 2018; 44: 1427-35.

2. Kahan BC, Koulenti D, Arvaniti K, et al. Critical care admission following elective surgery was not associated with survival benefit: prospective analysis of data from 27 countries. Intensive Care Med. 2017; 43: 971-9.

3. Onwochei DN, Fabes J, Walker D, Kumar G and Moonesinghe SR. Critical care after major surgery: a systematic review of risk factors for unplanned admission. Anaesthesia. 2020; 75 Suppl 1: e62e74.

4. Botto F, Alonso-Coello P, Chan MT, et al. Myocardial injury after noncardiac surgery: a large, international, prospective cohort study establishing diagnostic criteria, characteristics, predictors, and 30day outcomes. Anesthesiology. 2014; 120: 564-78.

5. Devereaux PJ and Sessler DI. Cardiac Complications in Patients Undergoing Major Noncardiac Surgery. New England Journal of Medicine. 2015; 373: 2258-69.

6. Gualandro DM, Puelacher $\mathrm{C}$ and Mueller $\mathrm{C}$. High-sensitivity cardiac troponin in acute conditions. Current opinion in critical care. 2014; 20: 472-7.

7. Korff S, Katus HA and Giannitsis E. Differential diagnosis of elevated troponins. Heart (British Cardiac Society). 2006; 92: 987-93.

8. Ohman EM, Armstrong PW, White HD, et al. Risk stratification with a point-of-care cardiac troponin T test in acute myocardial infarction. GUSTOIII Investigators. Global Use of Strategies To Open Occluded Coronary Arteries. The American journal of cardiology. 1999; 84: 1281-6.

9. Uchoa RB and Caramelli B. Troponin I as a mortality marker after lung resection surgery - a prospective cohort study. BMC anesthesiology. 2020; 20: 118.

10. van Geene Y, van Swieten HA and Noyez L. Cardiac troponin I levels after cardiac surgery as predictor for in-hospital mortality. Interactive cardiovascular and thoracic surgery. 2010; 10: 413-6.

11. Devereaux PJ, Biccard BM, Sigamani A, et al. Association of Postoperative High-Sensitivity Troponin Levels With Myocardial Injury and 30-Day Mortality Among Patients Undergoing Noncardiac 
Surgery. Jama. 2017; 317: 1642-51.

12. Gupta PK, Gupta H, Sundaram A, et al. Development and Validation of a Risk Calculator for Prediction of Cardiac Risk After Surgery. Circulation. 2011; 124: 381-7.

13. Humble CAS, Huang S, Jammer I, Björk J and Chew MS. Prognostic performance of preoperative cardiac troponin and perioperative changes in cardiac troponin for the prediction of major adverse cardiac events and mortality in noncardiac surgery: A systematic review and meta-analysis. PloS one. 2019; 14: e0215094.

14. Mauermann E, Puelacher $\mathrm{C}$ and Lurati Buse G. Myocardial injury after noncardiac surgery: an underappreciated problem and current challenges. Current opinion in anaesthesiology. 2016; 29: 403-12.

15. Conti D, Ballo P, Ruggiano P, Boccalini R, Pavoni V and Sarti A. Very early postoperative troponin increase and clinical outcome in patients admitted to the recovery room after noncardiac surgery with suspected cardiac events. Indian heart journal. 2020; 72: 197-9.

16. Cullen L, Mueller C, Parsonage WA, et al. Validation of high-sensitivity troponin I in a 2-hour diagnostic strategy to assess 30-day outcomes in emergency department patients with possible acute coronary syndrome. Journal of the American College of Cardiology. 2013; 62: 1242-9.

17. Mauermann E, Bolliger D, Fassl J, et al. Postoperative High-Sensitivity Troponin and Its Association With 30-Day and 12-Month, All-Cause Mortality in Patients Undergoing On-Pump Cardiac Surgery. Anesthesia and analgesia. 2017; 125: 1110-7.

18. González-Tallada A, Borrell-Vega J, Coronado C, et al. Myocardial Injury After Noncardiac Surgery: Incidence, Predictive Factors, and Outcome in High-Risk Patients Undergoing Thoracic Surgery: An Observational Study. Journal of cardiothoracic and vascular anesthesia. 2020; 34: 426-32.

19. Conti D, Ballo P, Boccalini R and Sarti A. Predictors of early postoperative troponin increase after noncardiac surgery: a pilot study in a real-world population admitted to the recovery room. British journal of anaesthesia. 2015; 115: 945-6.

\section{Figures}




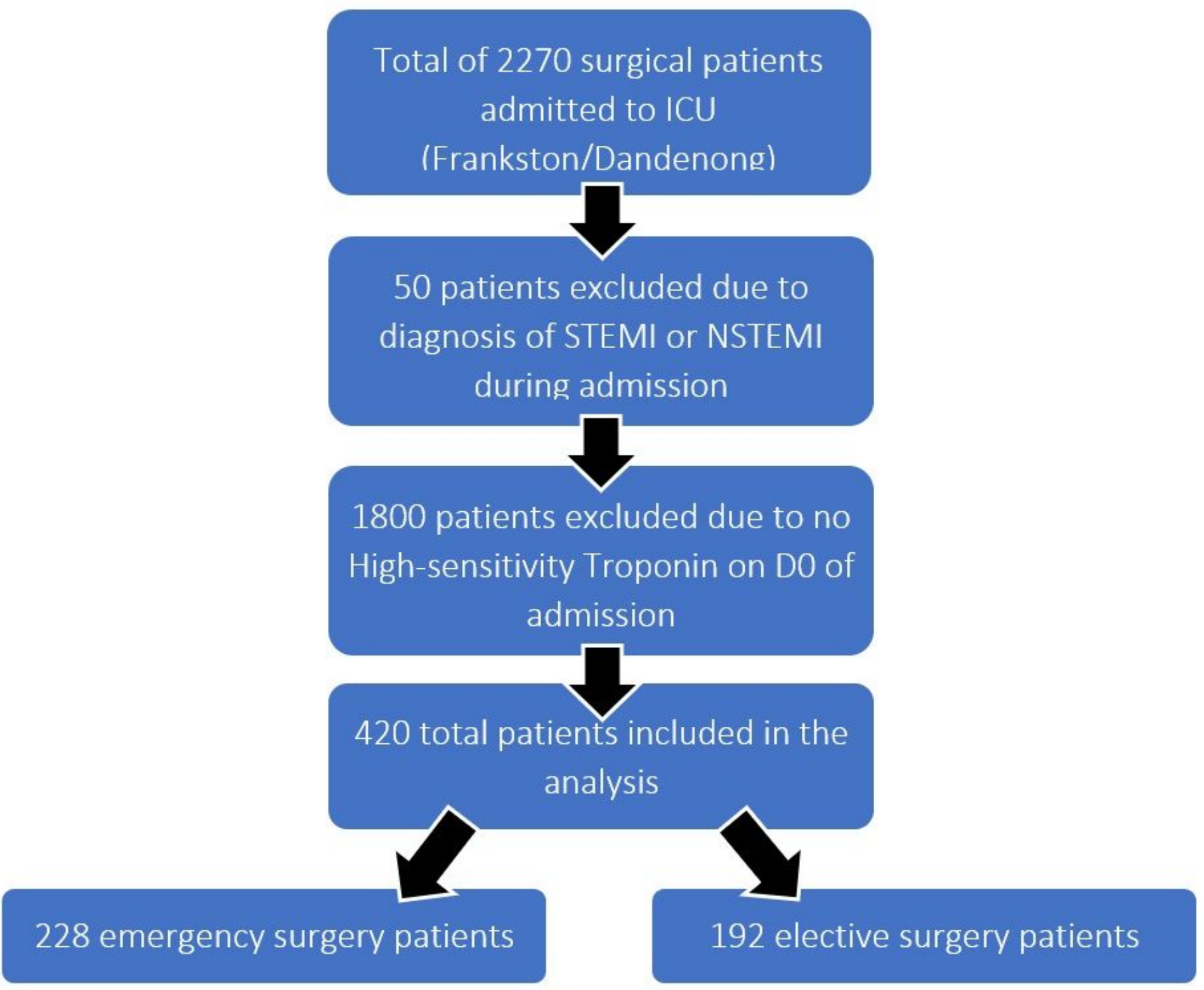

Figure 1

Study Profile 


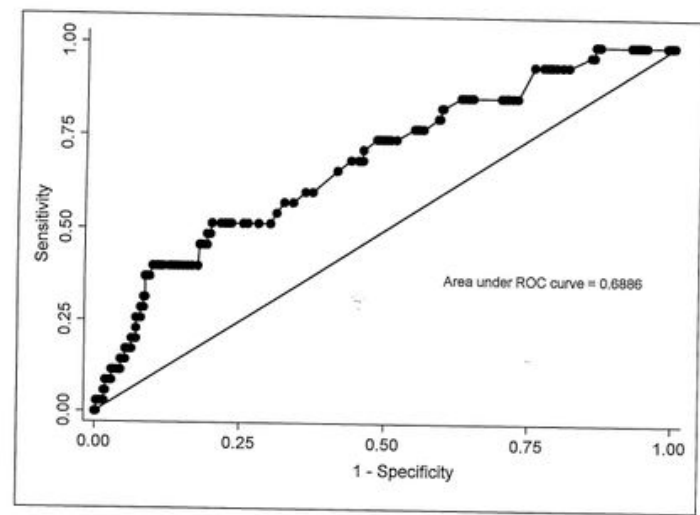

Figure 2a

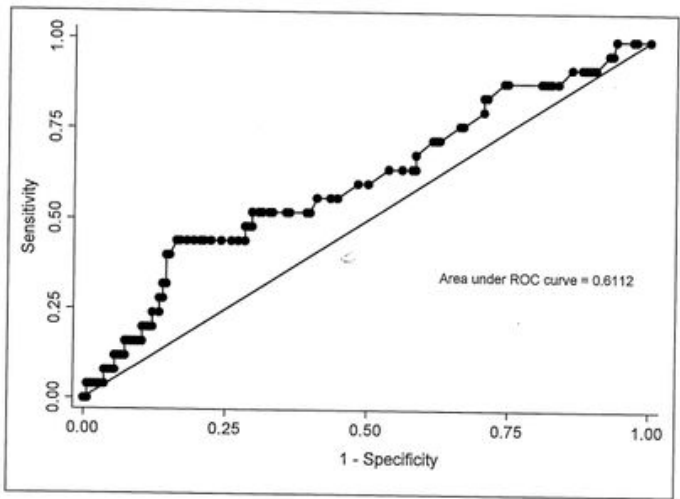

Figure $2 b$

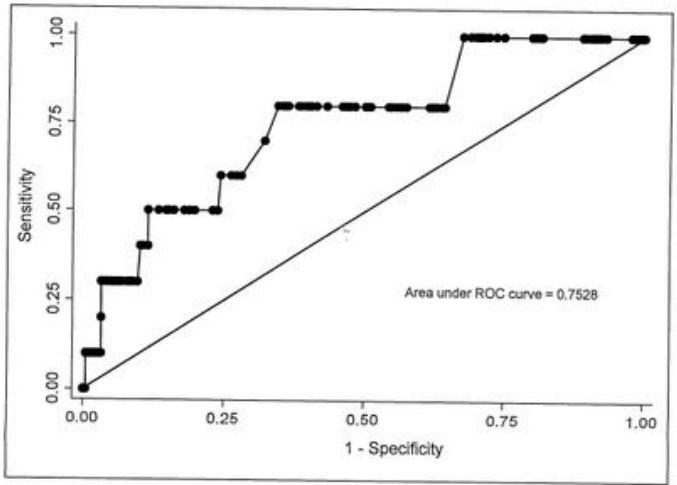

Figure 2c

\section{Figure 2}

Area under the receiver operating characteristic curves Top figure. ROC curve for highest troponin on day 0 (all patients) Middle figure. ROC curve for highest troponin on day 0 (Emergency surgery patients only) Bottom figure. ROC curve for highest troponin on day 0 (Elective surgery patients only) 